\title{
A trial derivation of seismic plate coupling by focusing on the activity of shallow slow earthquakes
}

\author{
Keisuke Ariyoshi ${ }^{*}$, Toru Matsuzawa ${ }^{2}$, Ryota Hino ${ }^{3}$, Akira Hasegawa ${ }^{2}$, Takane Hori $^{1}$, Ryoko Nakata ${ }^{1}$ \\ and Yoshiyuki Kaneda ${ }^{1,4}$
}

\begin{abstract}
To understand the effect of plate coupling on very low-frequency event (VLFE) activity resulting from megathrust earthquakes, we performed long-term multiscale earthquake cycle simulations (including a megathrust earthquake and slow earthquakes) on a 3-D subduction plate boundary model, based on a rate- and state-dependent friction law. Our simulation suggests that quiescence of shallow VLFEs off Miyagi may be explained by the location in the shallow central part of the 2011 Tohoku earthquake because of the locally strong coupling, while observed activation of VLFEs off Iwate (northern part of Tohoku district), Fukushima (southern part of Tohoku district), and Ibaraki (northern part of Kanto district) is explained by the location on the outer rim. The area and duration of the quiescence off Miyagi may be a new clue to evaluate the potential for plate coupling strong enough to cause the next megathrust earthquake.
\end{abstract}

Keywords: Subduction plate boundary; Megathrust earthquake; Rate- and state-dependent friction law; Superhydrostatic pressure

\section{Background}

Broadband seafloor seismometers near the trench (Sugioka et al. 2012) and dense inland networks of highly sensitive seismic stations (Matsuzawa et al. 2012) have enabled observation of very low-frequency earthquakes (VLFEs; Ito et al. 2007) in the shallow transition zone near the trench of subduction plate boundaries (Schwartz and Rokosky 2007) as well as a deep low-frequency earthquake (at a depth about $30 \mathrm{~km}$ ) (Obara and Sekine 2009). VLFEs are thought to be of a slow earthquake group with a constant moment rate function (Ide et al. 2007).

After the 2011 Tohoku earthquake (e.g., Yagi and Fukahata 2011), northeastern Japan (see Figure 1), Matsuzawa et al. (2012) reported that shallow VLFEs became active locally off the Iwate, Fukushima, and Ibaraki regions but were inactive off Miyagi. In addition, shallow VLFEs seemed to occur in isolation there, while VLFEs

\footnotetext{
* Correspondence: ariyoshi@jamstec.go.jp

${ }^{1}$ Research and Development Center for Earthquake and Tsunami, Japan Agency for Marine-Earth Science and Technology, Yokohama 236-0001, Japan

Full list of author information is available at the end of the article
}

migrated for long distances along the strike direction in the down-dip range of the seismogenic zone for the Nankai Trough (Obara and Sekine 2009), southwestern Japan, and around the up-dip range off Tokachi (e.g., NIED 2014), southern Hokkaido. The reasons for the differences in the location and activity of the VLFEs are not yet understood.

From numerical simulations of VLFEs on the basis of a rate- and state-dependent friction (RSF) law (Dieterich 1979; Ruina 1983) derived from rock laboratory experiments, Ariyoshi et al. (2012) pointed out that the recurrence interval of VLFEs decreases and the moment release rate increases during the preseismic stage of megathrust earthquakes. Slow-slip events (SSEs), another type of slow earthquake with longer duration than VLFE, have also been modeled in recent studies, which have succeeded in reproducing SSE migration (Shibazaki and Shimamoto 2007) and have shown that the recurrence interval of SSEs also decreases during the preseismic stage of megathrust earthquakes (Matsuzawa et al. 2010).

These simulation results could not directly explain why the VLFEs were inactive off Miyagi, when large postseismic 


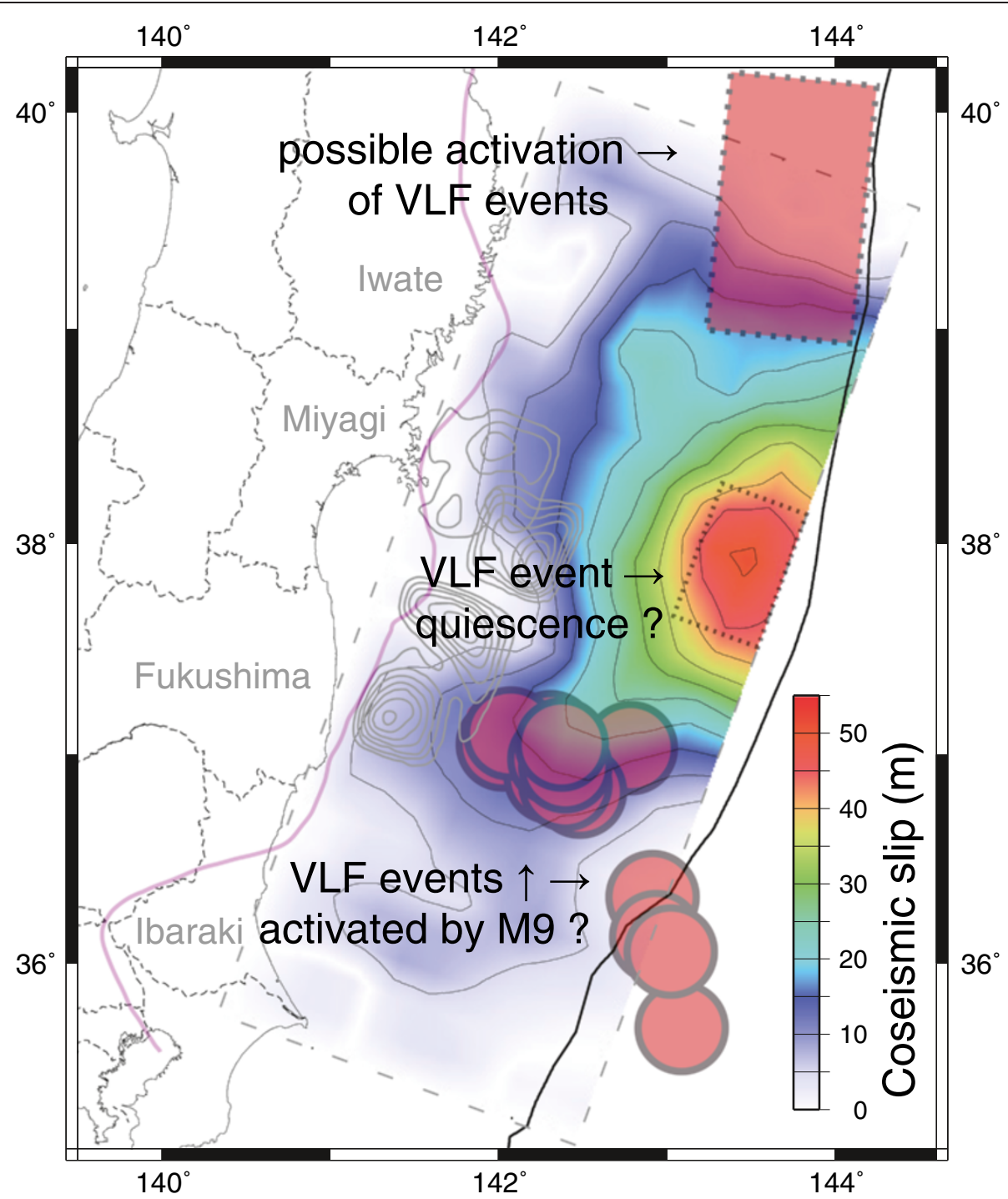

Figure 1 Overview of the 2011 Tohoku earthquake and localization of shallow slow earthquakes. Red circles were determined by NIED (2012). Coseismic slip is indicated by a color scale (Yagi and Fukahata 2011). The gray contours denote the slip areas for the recent major earthquakes at Miyagi-oki in 1978 (M7.4) and 1936 (M7.4), and at Fukushima-oki in 1938 (M7.3, M7.4, and M7.5; Murotani 2003; Yamanaka and Kikuchi 2004). The gray broken lines denote the borders of Iwate, Miyagi, Fukushima, and Ibaraki prefectures. Gray and pink bold lines denote the trench axis and the down-dip limit of interplate earthquakes (Igarashi et al. 2001; Uchida et al. 2009). Rectangles with broken lines represent our suggestions based on the present study as described in the 'Discussion' section.

slip occurs around megathrust earthquakes, which is thought to promote VLFEs. Another question is whether the local difference in the shallow VLFE activity off Tohoku may be partly explained by the inhomogeneity of the frictional properties (Matsuzawa et al. 2012). This seems to be inconsistent with VLFE migration at depth, if the frictional property in the shallower part of the transition zone is largely homogenous along the strike direction in the same way as the deeper earthquake (e.g., Schwartz and Rokosky 2007), in which the VLFE migrates for long distances (Obara and Sekine 2009). This is because VLFE migration can be easily reproduced when the frictional properties are homogenous or weakly inhomogeneous along the strike direction, as shown in numerical simulations (e.g., Ariyoshi et al. 2009; Shibazaki and Shimamoto 2007). The stress shadow effect, which is the relationship of present observations of low seismicity rates with the occurrence of past large earthquakes in major asperities (e.g., Maccaferri et al. 2013), may be another factor of VLFE localization. Previous studies have not investigated this effect.

In this study, we perform numerical simulations of multiscale earthquake cycles, including a megathrust earthquake and VLFEs, on a three-dimensional subduction plate boundary with high spatiotemporal resolution to understand the change in activity of VLFEs after megathrust earthquakes. 


\section{Methods}

Outline of modeling slow earthquakes under different plate coupling conditions

The numerical simulation employed in the present study is similar to that described by Ariyoshi et al. (2013). In our study, the motion equation for a subduction plate boundary is described by a quasi-dynamic equilibrium (e.g., Rice 1993) between the shear stress (due to reverse dip slip on the discretized faults) and the frictional stress based on an RSF law. It is well known that RSF laws can represent asperity models (Lay et al. 1982; Scholz 1990), where an asperity is an area on a stuck fault. An earthquake rupture usually begins at an asperity because of friction gap. From the various friction laws available, we adopted the aging (or slowness) law, which enabled us to reproduce slow earthquakes under the condition of weak frictional instability, which was relatively easier than the slip law, as pointed out by Ampuero and Rubin (2008). The details are described later.

To perform multiscale earthquake cycle simulations, we assumed a single large asperity and numerous small asperities arranged along the strike direction, as shown by the blue patches $(\gamma=a-b<0)$ in Figure 2, where $a$ and $b$ are frictional parameters and $\gamma<0$ means velocity weakening (Ruina 1983). In our model, a large asperity generates megathrust earthquakes and a chain reaction of numerous small asperities generates a migration of slow earthquakes along the strike direction (Ariyoshi et al. 2009). The difference of slip behavior between the regular earthquake (including the megathrust

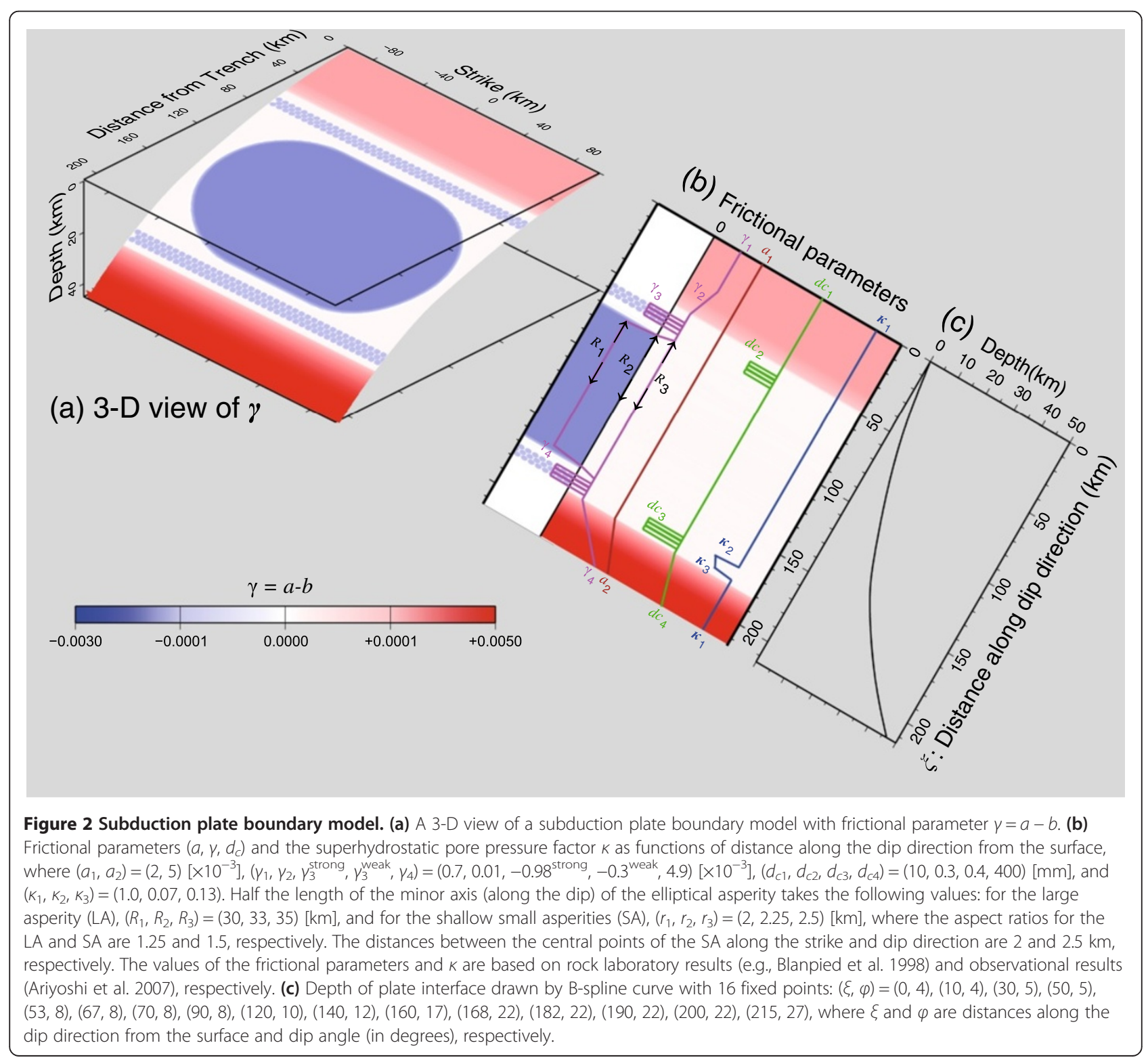


earthquake) and slow earthquakes is explained by asperity size $r$ or $R$ (hereafter, we represent it as $L$ ) relative to nucleation size, where $r$ and $R$ are half the length of the minor axis (along the dip) of the elliptical large and small asperities in Figure 2, respectively. For the aging law, a slip event does not occur in the asperity but creeps at a steady rate for $L<L_{\mathrm{min}}$. A slow earthquake occurs for $L_{\min }<L<L_{\infty}$, and a regular earthquake occurs for $L_{\infty}<L$, where asymptotic nucleation half-length $L_{\infty}=\eta G b d_{c} / \sigma \gamma^{2}$ and minimum nucleation half-length $L_{\min }=\eta G d_{c} / \sigma(b-a)$ for $\gamma<0$ (Ampuero and Rubin 2008); $\eta, G$, and $\sigma$ are geometrical factor, rigidity, and effective normal stress, respectively. This means that frictional instability becomes higher for higher effective normal stress and shorter characteristic slip distance.

To evaluate the stress shadow effect around megathrust earthquakes, we had to estimate the state of plate coupling, where plate coupling $X$ is defined as Coseismic slip/Total slip for one cycle of the megathrust earthquake (e.g., Kato and Hirasawa 1997) or 1 - Present slip rate $V /$ Plate convergence rate $V_{\mathrm{pl}}$ (e.g., Hyndman et al. 1997). On the relation between the plate coupling and the frictional parameters of RSF law, it is well known that the degree of the plate coupling has a strongly negative correlation with the value of $L_{\min }$ (e.g., Kato and Hirasawa 1997), if we assume a fixed size of asperity. In this study, we chose two models: a strong coupling model (SCM) and a weak coupling model (WCM). The WCM is the model adopted by Ariyoshi et al. (2013) for the 1944 Tonankai earthquake. The SCM is the same as the WCM, except that the frictional stability parameter $\gamma$ for large asperity is about 2.6 times greater under the higher value of the frictional parameter $b$ in the RSF law.

For generating slow earthquakes that migrate along the strike direction in both the deep and shallow belts of small asperities, we assumed that $\sigma$ is described as $\sigma=\kappa$ ( $\left.\sigma^{\text {litho }}-\sigma^{\text {hydro }}\right)$, where $\kappa, \sigma^{\text {litho }}$, and $\sigma^{\text {hydro }}$ are a superhydrostatic factor (Ariyoshi et al. 2007, 2012), lithostatic pressure, and hydrostatic pressure, respectively. We also assumed that, locally, $\sigma$ has a low value of about $30 \mathrm{MPa}$ due to the existence of high pore pressure at a depth near $30 \mathrm{~km}$; we did this by setting the local value of $\kappa$ to about 0.1 (Ariyoshi et al. 2007), as shown in Figure 2. We will discuss this in more detail in the 'Discussion' section.

There is a large difference in scale between large and small asperities, and unless one has an effective strategy, there is a huge calculation cost to repeatedly generating megathrust earthquakes (e.g., Rice 1993). To simplify the model, we assumed that the direction of plate bending and shear displacement was only along the dip direction. Considering previous structural surveys (e.g., Nakanishi et al. 2008), we assume that the dip angle gradually increases from $4^{\circ}$ (at the surface) to $27^{\circ}$ (at the bottom of the target region), and plate shape is drawn by the B-spline curve, as shown in Figure 2c. Subduction plate motion was represented by a back-slip model (Savage 1983), and it was assumed to be uniform at a rate of $V_{\mathrm{pl}}=4 \mathrm{~cm} /$ year, which means that the plate boundary beneath the model region shown in Figure 2a is also subducting at a rate of $V_{\mathrm{pl}}$. This is seen in the oceanic trenches of Nankai, Sumatra, and Chile, where there are several sources of megathrust earthquakes adjacent to each other along the trenches (e.g., Furumura et al. 2011; Wiseman and Bürgmann 2011; Hayes et al. 2013). To represent the migration of slow earthquakes over the model region, as well as the effect of neighboring megathrust earthquakes, we assumed a periodical condition along the strike direction.

These simplifications enabled us to make great calculation savings by taking advantage of fast Fourier transforms (FFT) based on Green's function (Okada 1992) when calculating the shear stress, for the dip slip on the array of subfaults along the strike direction (Rice 1993; Ariyoshi et al. 2012). By simplifying the model conditions and using the vectorized multi-FFT algorithm on the Earth Simulator supercomputer, we were able to conduct large-scale simulations of a multiscale earthquake cycle on the subduction plate, divided into

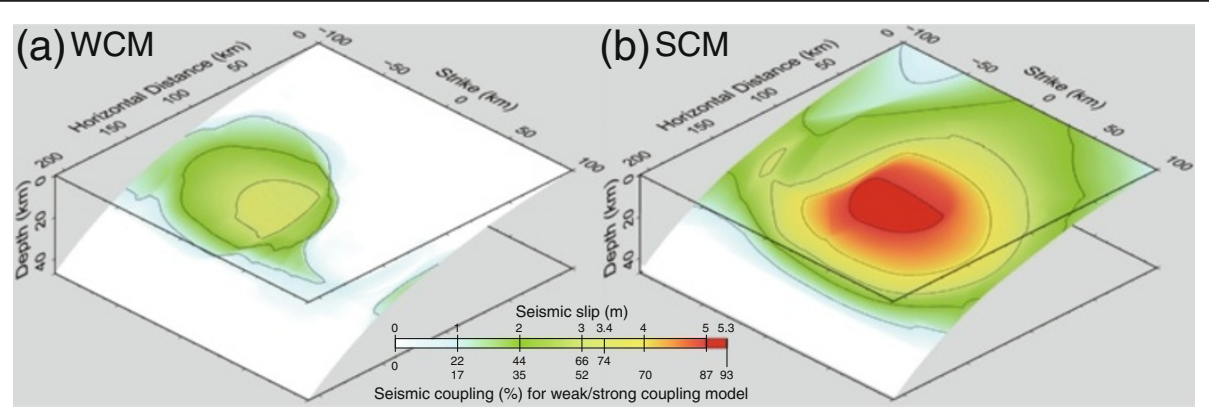

Figure 3 Slip isograms (0.5-m increments) of the simulated megathrust earthquakes. (a) WCM and (b) SCM, with a color scale. The seismic coupling ratio is defined as Coseismic slip/ $\left(V_{\mathrm{pl}} \times T_{\mathrm{r}}\right)$; the conversion is listed on the scale bar. 
$1,210,368$ subfaults $[2,048$ (strike) $\times 591$ (dip)], where cell sizes $\left(h^{\text {strike }}, h^{\text {dip }}\right)$ for the small asperities and the large asperity are $(0.1,0.5)$ and $(0.1,0.1)[\mathrm{km}]$, respectively. This was smaller than critical mesh size $L_{b}=\eta G d_{\mathrm{c}} / \sigma b$ (Rubin and Ampuero 2005), where $\eta=1.38$ (Shibazaki and Shimamoto 2007), $G=30 \mathrm{GPa}, d_{c}=d_{c 1}=10$ and $d_{c 2}=0.3[\mathrm{~mm}], \sigma=30 \mathrm{MPa}, b=a_{1}-\gamma_{3}=2.3\left[\times 10^{-3}\right]$, $L_{b}^{\text {large }}=6[\mathrm{~km}]$, and $L_{b}^{\text {small }}=0.18[\mathrm{~km}]$, and sufficiently fine that the numerical simulation results are independent of the mesh size, as determined by comparing with several other models with the mesh size changed.

\section{Results}

\section{Effect of a strong coupling model on the activity of shallow VLFEs}

Figure 3 shows the spatial distribution of the coseismic slip (defined to be faster than $3 \mathrm{~cm} / \mathrm{s}$, in accordance with Ariyoshi et al. 2013) of the simulated megathrust earthquake that occurred in the large asperity, which is almost characteristic. The asymmetric distribution of the coseismic slip is due to the asymmetry at the edge of the small asperity belt, as shown in Figure 2. For the SCM and the WCM, the recurrence intervals of a megathrust earthquake $\left(T_{\mathrm{r}}\right)$ were 143 and 113 years, respectively, and its moment magnitudes $\left(M_{w}\right)$ were 8.3 and 7.9, respectively. With $T_{\mathrm{r}}, V_{\mathrm{p}}$, and the amount of coseismic slip, we can calculate the plate coupling ratio as described in the caption of Figure 3.

From Figure 3, we see that the megathrust earthquake of the SCM ruptures in and around the large asperity, penetrating to the trench, as was observed in the 2011 Tohoku earthquake (Yagi and Fukahata 2011), while that of the WCM ruptures only part of the large asperity, as was seen in the 1944 Tonankai earthquake (Kikuchi et al. 2003) and the 2003 Tokachi earthquake (Yamanaka and Kikuchi 2003).

To understand the reasons for the coseismic slip penetrating to the trench far away from the large asperity, we show snapshots of the slip velocity (normalized by $V_{\mathrm{pl}}$ on the common logarithmic scale) on the plate boundary in the interseismic (Figure 4a,c) and preseismic (Figure 4b,d) stages of a megathrust earthquake, where the interseismic stage is considered to be about half of $T_{\mathrm{r}}$ (70 and 50 years for SCM and WCM, respectively) and the preseismic stage is considered to be 10 years before the onset of a megathrust earthquake.

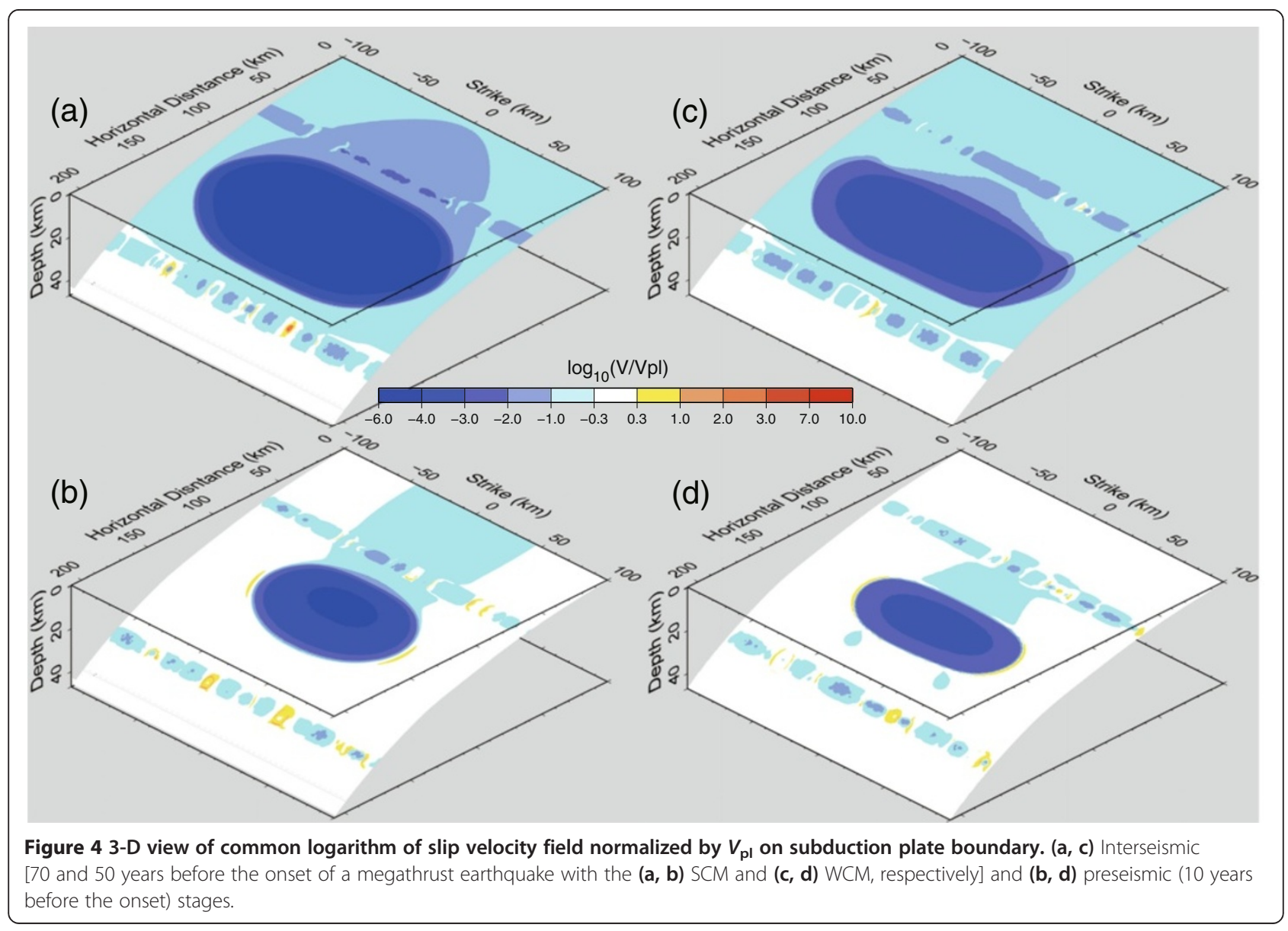


As mentioned before, temporal plate coupling is calculated by $1-V / V_{\mathrm{pl}}$. Therefore, blue and white colors in Figure 4 represent strong and weak coupling, respectively, while yellow and red colors represent aseismic and coseismic slip, respectively [both are forward slip (Savage 1983)].

Figure 4 shows that the strong plate coupling due to the stress shadow indicated by blue color extends to the trench for the SCM but not for the WCM. This suggests that in the SCM, the coseismic slip is caused by the accumulation of a slip deficit near the trench during the interseismic stage, in a region where the stress shadow effect is greater than it is in deeper regions, due to the free surface, which is investigated later.

From Figure 4, we see that the plate coupling is more affected in the shallower regions than in the deeper regions, in which the SCM predominates. To investigate the effect of this difference on slow earthquake activity, we show the spatiotemporal evolution of the slip velocity (normalized by $V_{\mathrm{pl}}$ ), focusing on the shallow and deep belts of small asperity along the strike direction. This is shown for the WCM in Figure 5a,b and for the SCM in Figure 5c,d,e,f,g,h.

In Figure $5 \mathrm{a}, \mathrm{b}, \mathrm{d}$, the migration of slow earthquakes is shown by streaks of warm colors (i.e., yellow through red; see the close-up in Figure 5e,f,g,h), which are mainly composed of VLFEs, as demonstrated by Ariyoshi et al. (2012, 2013). As confirmed by other trial simulations, if frictional instability in the small asperities is greater that is, the value of $\gamma_{3}$ and/or $\kappa_{2}\left(\kappa_{3}\right)$ is greater - slip events in the belt of the small asperities approach from slow earthquake to regular earthquake, which is consistent with results of recent simulations (e.g., Shibazaki and Shimamoto 2007; Matsuzawa et al. 2010; Ariyoshi et al. 2009; Ariyoshi et al. 2012) and theoretical analysis of nucleation sizes $L_{\min }$ and $L_{\infty}$ (Ampuero and Rubin 2008).

With the WCM, Figure 5a,b shows that migration occurs in the shallow belt of small asperity as well as in the deep belt, which is more active from about 10 years before until several years after a megathrust earthquake, due to stress field promotion driven by preseismic and postseismic slips around the large asperity (Ariyoshi et al. 2012). With the SCM, however, Figure 5c shows there is a quiescence in slow earthquakes that appears on the shallow belt during the interseismic stage (about 0 to +40 years), where the whole region is aqua except for the central part, which is blue (|Strike $\mid<30 \mathrm{~km})$, and there are no streaks of warm colors. This is due to strong plate coupling, as shown in Figure 4a. From other additional simulations, in which we varied the nucleation length of $L_{\min }$ and $L_{\infty}$ in the large asperity by changing the frictional parameters $b=\left(a_{1}-\gamma_{4}\right)$ and $d_{c 1}$ for the large asperity, the lower frictional instability of the large asperity caused the quiescence of the VLFEs to be shorter in time and smaller in space because of the
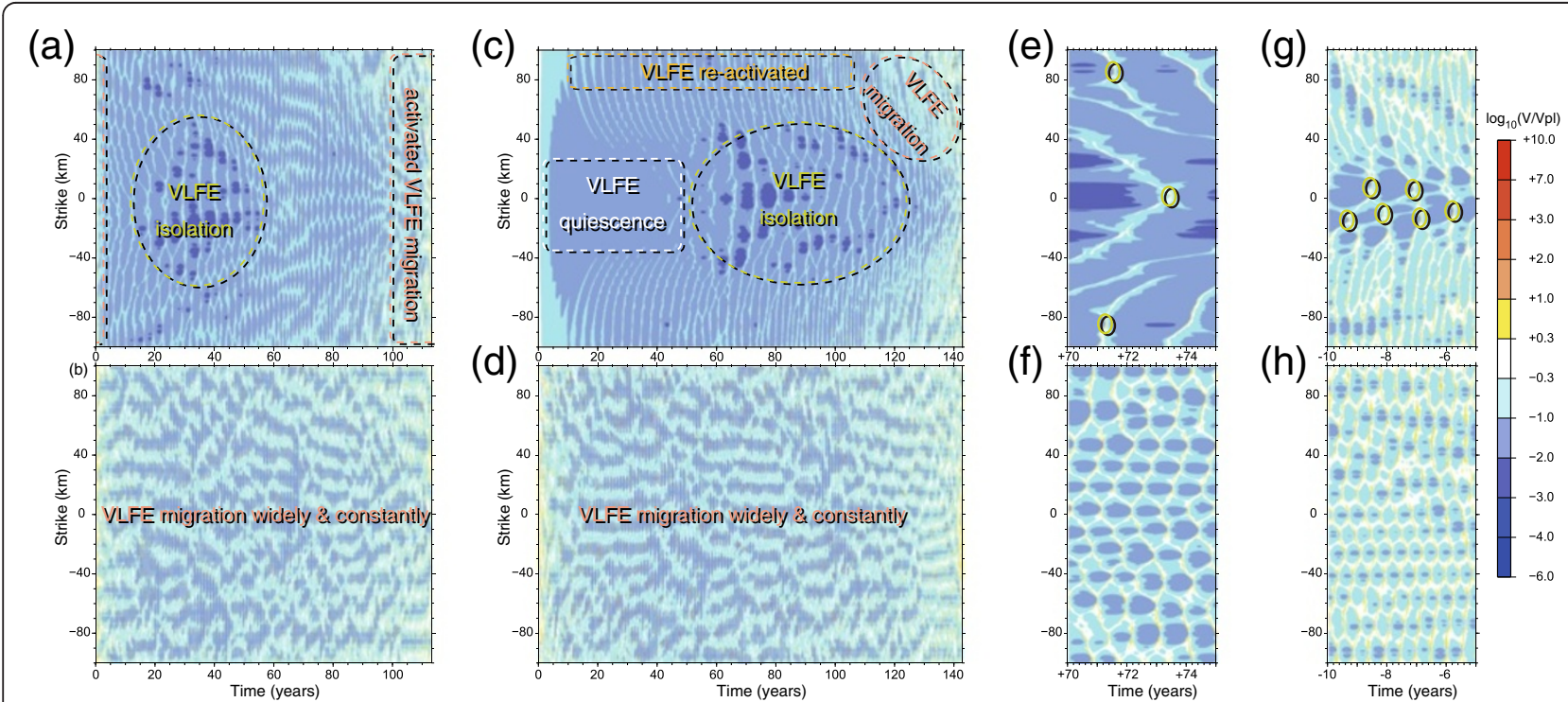

Figure 5 Spatiotemporal evolution of the slip velocities. Spatiotemporal evolution of the slip velocities at $\xi=60$ and $175 \mathrm{~km}$ along the dip direction (see Figure $2 b$ ), where lie, respectively, shallow $(\mathbf{a}, \mathbf{c}, \mathbf{e}, \mathbf{g}$ ) and deep $(\mathbf{b}, \mathbf{d}, \mathbf{f}, \mathbf{h})$ belts of small asperity. (a-d) Overview for one cycle of a megathrust earthquake with the WCM (a, $\mathbf{b})$ and the SCM (c, $\mathbf{d})$. (e-h) Close-up of the SCM for the interseismic $(\mathbf{e}, \mathbf{f})$ and preseismic $(\mathbf{g}, \mathbf{h})$ stages The initial time is taken as the onset of a megathrust earthquake. The time scale ratio is the same for both the WCM and the SCM. The scale colors are the same as in Figure 4. Green ellipses indicate isolated VLFEs. 
weaker plate coupling (e.g., Kato and Hirasawa 1997). This will be further discussed later.

For slow earthquakes, when comparing shallow (Figure 5e,g) and deep (Figure 5f,h) belts of small asperity, we find that isolated slow earthquakes occur on the shallow belt, as indicated by the green ellipses and that slow earthquake migration becomes active, especially away from the central region (|Strike $\mid>80 \mathrm{~km}$ ). We also see that slow earthquake migration occurs widely and continuously on the deep belt, with the approaching onset of a megathrust earthquake, as pointed out by Ariyoshi et al. (2012). To solve the questions raised in the 'Background' section, we will apply these results (in the next section) to the VLFE activity observed off Tohoku.

\section{Discussion}

Interpretation of activity change of VLFEs off Tohoku

Figure 1 shows the coseismic slip distribution estimated by Yagi and Fukahata (2011) for the 2011 Tohoku earthquake, the epicenters of the following VLFEs, and our interpretations. In Figure 1, the epicenters of the very lowfrequency (VLF) after-events off Fukushima and Ibaraki were primarily located on the outer rim of the coseismic slip of the 2011 Tohoku earthquake. This location of the VLFEs may be explained as a reactivation in the outer part ( $\mid$ Strike $\mid>80 \mathrm{~km})$, as shown in Figure 4c. Figures 3a and $4 \mathrm{c}$ also suggest a quiescence of the VLFEs around the center of strong plate coupling, which may correspond to the fact that VLF after-events were not observed off Miyagi (Matsuzawa et al. 2012). We can also expect activation off Iwate, on the opposite side of the main source region, which gives us a clue for finding previously undiscovered VLFEs from very large events.

As mentioned in the 'Results' section, our simulation results show that VLFE quiescence correlates with the degree of frictional instability in the large asperity. From Figure 5, we see that in the SCM, the duration time of the shallow VLFE quiescence $\left(T_{\mathrm{q}}\right)$ is about 40 years, with $T_{\mathrm{r}}$ about 140 years. The ratio $T_{\mathrm{q}} / T_{\mathrm{r}}$ seems high, which is due to the strong frictional instability that covers the entire large asperity, as shown in Figure 2a. This assumption may differ from the situation in the 2011 Tohoku earthquake, because the estimated strong-coupled region is thought to be a portion of the main fault off Miyagi, as shown in Figure 1. With the SCM, the frictional parameters $\left[a_{1}, b=\left(a_{1}-\gamma_{4}\right)\right]$ in the large asperity were (2.0, 2.98) $\left[\times 10^{-3}\right]$, which is thought to be a case of the possible largest value of $b$, because laboratory experiments suggest that $b$ is comparable with $a$ (e.g., Blanpied et al. 1998). In addition to these conditions, considering that $T_{\mathrm{q}} / T_{\mathrm{r}}$ becomes higher when the nucleation lengths $L_{\mathrm{min}}$ and $L_{\infty}$ are shorter (or frictionally more unstable) in a wider range, we think that the SCM is a possible case that produces the highest value for $T_{\mathrm{q}} / T_{\mathrm{r}}$.

Free-surface condition is another factor affecting $T_{\mathrm{q}} /$ $T_{\mathrm{r}}$. To evaluate free-surface condition, we performed another SCM simulation in a full-space elastic medium, so as to remove the free-surface condition (hereafter, we call it SCMF). In the SCMF, the values of $T_{\mathrm{r}}$ and $M_{w}$ are 95.1 and 8.1 years, respectively. Figure 6a,b shows the normalized slip velocity field in the interseismic and preseismic stages of the megathrust earthquake as similar to Figure 4, which are significantly different from Figure 4, in that the distribution of the locked region (cool colors) is largely symmetric between shallower and deeper parts around the large asperity. This result suggests that the stress shadow of the megathrust earthquake for shallower parts is amplified mainly by the free-surface condition, which brings about shorter recurrence intervals than SCM. Figure 6c,d shows the longterm spatiotemporal evolution of the normalized slip velocity as similar to Figure 5a,b,c,d. Compared with Figure $5 \mathrm{a}, \mathrm{c}$, Figure $6 \mathrm{c}, \mathrm{d}$ shows that the quiescence of slow earthquakes just after the megathrust earthquake is weaker (light aqua color) and its span (the value of $\left.T_{\mathrm{q}} / T_{\mathrm{r}}\right)$ is significantly shorter than that of SCM. This result means that the quiescence of slow earthquakes reflects not only frictional instability for megathrust earthquakes, but also the stress shadow effect amplified by the free surface.

Considering these results, we propose that the duration and the spatial range of the VLFE quiescence observed off Miyagi may be a new tool to monitor the state of plate coupling by applying the value of $T_{\mathrm{q}} / T_{\mathrm{r}}$ (about 1/3 for the highest case) to actual megathrust earthquakes. If the quiescence lasts longer than 100 years ( $T_{\mathrm{q}}=100$ years), it would be further evidence that the 2011 Tohoku earthquake is a recurrence of the 869 Jogan earthquake (e.g., Ozawa et al. 2011), because $T_{\mathrm{r}}$ should be greater than 300 years. Note that this monitoring is independent of marine geodetic observations (e.g., Sato et al. 2011; Kido et al. 2011) which have a limited number of seafloor stations.

As mentioned in the 'Methods' section, the WCM is based on the 1944 Tonankai earthquake (Ariyoshi et al. 2013), and the SCM is based on the same location of asperity and plate shape as the weak coupling model. This means that the location and size of the large asperity are not based on the 2011 Tohoku earthquake, where the peak of the coseismic slip was located near the trench and had a significantly greater amount of slip, as shown in Figure 1. To discuss quantitatively the change in activity of the VLFEs, we need a more realistic threedimensional model (e.g., Shibazaki et al. 2011). We intend to pursue this topic in a future study. 

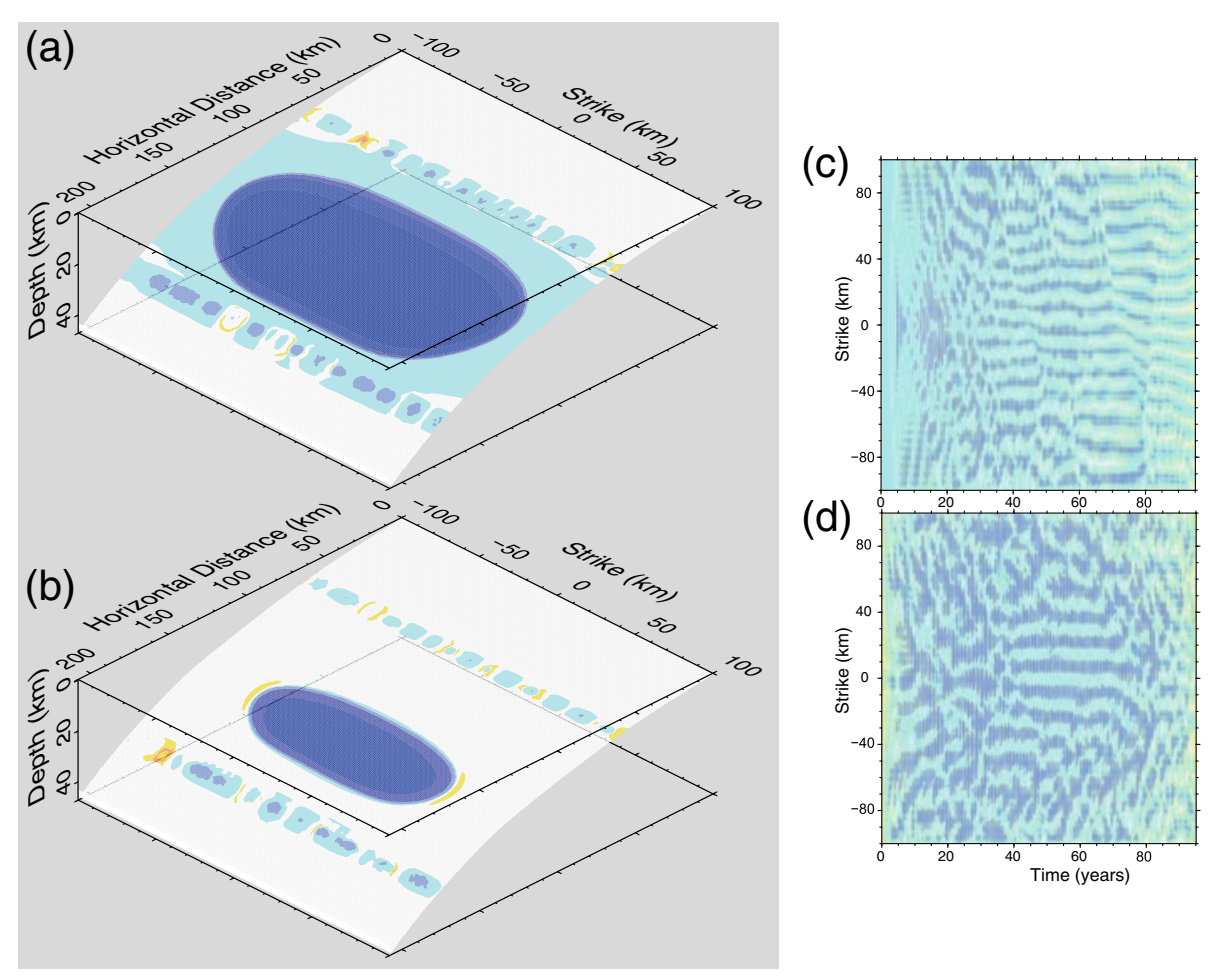

Figure 6 Normalized slip velocity and spatiotemporal evolution for the SCMF. (a, b) Same as Figure 4 for SCM in a full elastic medium (SCMF, without free surface conditions) in the (a) interseismic (40 years before the onset) and (b) preseismic (10 years before the onset) stages $(\mathbf{c}, \mathbf{d})$. Overview of the spatiotemporal evolution of the slip velocities as similar to Figure $5 a, b, c, d$ for one $c y c l e\left(T_{r}=95.1\right.$ years $)$ of a megathrust earthquake in case of SCMF.

Focusing on the shallower part of the plate coupling in Figure 4, we find that the stress shadow effect depends on the distance along the dip as well as along the strike, as discussed in Figure 1. Recently, shallow VLFEs with migration have been observed off Tokachi (e.g., NIED 2014), northward from off Tohoku, where megathrust earthquakes have occurred in 1952 and 2003 (Yamanaka and Kikuchi 2003). The estimated hypocenters of VLFEs determined by NIED (2014) seem to have some dispersion along the dip direction as well as the strike direction, though they use only inland observations. If this is true, it means that we have to consider the dependency of the along-dip distance on the stress shadow effect as well as the along-strike distance from the source region of megathrust earthquakes.

On the deep belt of VLFEs, Figure 5 shows that the VLFEs migrate continuously and widely, which is consistent with observations off southwestern Japan at a depth of about $30 \mathrm{~km}$ (Obara and Sekine 2009), but deep VLFEs have not yet been observed off Tohoku. Figure 1 shows the down-dip limit of the interplate earthquakes off Tohoku. Their depth is about $60 \mathrm{~km}$, as shown by the pink bold line. The $M 7$-class interplate earthquakes occur in the locations indicated by gray contours near the down-dip limit lines. These results are significantly deeper than off southwestern Japan, where deep VLFEs occur at about $30 \mathrm{~km}$ (Obara and Sekine 2009). Since large (M7-class) earthquakes and slow earthquakes (including VLFEs) are thought to occur in the frictionally unstable $(\gamma<0)$ and transition zones $(\gamma \sim 0)$ of subduction plate boundaries (e.g., Schwartz and Rokosky 2007), respectively, this may be the reason for the difference in the observed deep VLFE activity between off Tohoku and southwestern Japan, from the view of frictional transition depth (Evans and Meade 2012).

As described in the 'Methods' section, the generation of VLFE depends on the nucleation sizes $L_{\min }$ and $L_{\infty}$ described as a function of the effective normal stress $\sigma$ and the characteristic slip distance $d_{c}$, in addition to frictional stability $\gamma$. However, we have not yet robustly estimated the actual value of the characteristic slip distance because the characteristic slip distance is very different in a rock laboratory experiment and in an actual fault of a megathrust earthquake, while the frictional parameters $a$ and $b$ are dimensionless. Therefore, the existence of a zone with high pore pressure is also thought to play an important role in constraining the condition of slow earthquake generation (Obara and Sekine 2009).

In our model, the characteristic slip distance for numerous small asperities $\left(d_{c 2}, d_{c 3}\right)$ is assumed to be 0.3 to 
$0.4 \mathrm{~mm}$, which is significantly shorter than other simulation studies (e.g., Matsuzawa et al. 2010; Shibazaki and Shimamoto 2007), which assume a characteristic distance to be 4 to $10 \mathrm{~mm}$. This difference is derived from uncertainty about the effective normal stress and pore pressure, where the effective normal stress in an SSE patch at a depth of $30 \mathrm{~km}$ for Matsuzawa et al. (2010) and Shibazaki and Shimamoto (2007) is assumed to be about 2 to $5 \mathrm{MPa}$, so as to keep the value of $L_{\text {min }}$ and $L_{\infty}$ nearly constant.

Off southwestern Japan, high pore pressure may exist locally around a depth of $30 \mathrm{~km}$, based on tomographic studies (Kato et al. 2010) and rock experiments (Katayama et al. 2012). Off Tohoku, Hasegawa et al. (2011) estimated that the fault strength of the 2011 Tohoku earthquake $\left(M_{w}\right.$ 9: fault size about $200 \mathrm{~km} \times$ $500 \mathrm{~km}$ ) was macroscopically 21 to $22 \mathrm{MPa}$. Because the depth range of the fault for the 2011 Tohoku earthquake is about 10 to $50 \mathrm{~km}$, the estimated fault strength is significantly weak for their depth, from the perspective of rock laboratory experiments under dry conditions (e.g., Kohlstedt et al. 1995). Ariyoshi et al. (2007) pointed out that the observed postseismic slip propagation, at a rate of about $10 \mathrm{~km} /$ month in the deep region $(>30-\mathrm{km}$ depth) for large interplate earthquakes, can be quantitatively explained by the lower value of the superhydrostatic factor $\kappa$ (about 0.1 to 0.2 ).

These results suggest that the zone of high pore pressure in the subduction plate boundary off Tohoku may be widespread rather than local, as they are off southwestern Japan. Thus, detailed mapping of the geofluid (e.g., Iwamori and Nakakuki 2013) is necessary to understand the differences between the slow earthquake activity off Tohoku, southwestern Japan, and the slow earthquake activity of other subduction zones across the globe (e.g., Schwartz and Rokosky 2007). These data can then be incorporated into more fully developed numerical simulations in future studies.

\section{Conclusions}

Our simulation results are summarized in the following:

(i) For a megathrust earthquake in which the coseismic slip penetrates to the trench, plate coupling in the postseismic stage will be strong in the region from the central part of the source region to the shallower part toward the trench, which will cause the shallow VLF after-events to be quiescent or to occur infrequently in isolation. On the outer rim, shallow VLF after-events will be reactivated earlier than they will be in the center because of weak plate coupling.

(ii) The local differences in shallow VLFE activity can be explained by plate coupling perturbations resulting from the stress shadow effect of megathrust earthquakes with strong plate coupling, even if the frictional property is macroscopically homogeneous in the belt of small asperities along the strike direction.

(iii) When the down-dip limit of an interplate earthquake or a frictional transition zone is as deep as $30 \mathrm{~km}$, deep VLFEs occur repeatedly and migrate for long distances along the strike direction. This is because the free-surface effect that amplifies the stress shadow is significant only in the shallow part.

By applying items (i), (ii), and (iii) to the 2011 Tohoku earthquake, we are able to interpret observed VLFE activity off Tohoku, as follows:

(iv) The activated region around the hypocenters of shallow VLF after-events off Iwate, Fukushima, and Ibaraki may indicate the outer rim of the source region of the 2011 Tohoku earthquake, while the quiescent zone off Miyagi may indicate the center side of the source region.

(v) The duration and the spatial range of future quiescent regions off Miyagi are expected to reveal the strength and size of plate coupling, which may be a new clue to evaluate the potential for local plate coupling to be strong enough to cause the next megathrust earthquake.

\section{Competing interests}

The authors declare that they have no competing interests.

\section{Authors' contributions}

KA formulated numerical simulation code of the interplate earthquake cycle on a subducting plate boundary and drafted the manuscript. TM and $\mathrm{AH}$ contributed to the discussion about the role of geofluid in generating slow earthquakes and the availability of the supercomputing resources at the Cyberscience Center of Tohoku University. $\mathrm{RH}$ reviewed the manuscript from the view of oceanic observations. TH and RN discussed the activity change of slow earthquakes in relation to megathrust earthquakes. YK contributed to the availability of the Earth Simulator and seafloor observation (DONET). All authors read and approved the final manuscript.

\section{Acknowledgements}

The authors thank the DONET project members for fruitful discussions. The present study used the Earth Simulator and the supercomputing resources at the Cyberscience Center of Tohoku University. GMT software (Wessel and Smith 1998) was used to draw a number of the figures. The comments of two anonymous reviewers helped improve our manuscript. We are obliged to the editor Junichi Nakajima for expeditious handling. This study was partly supported by the MEXT for Geofluids program and the JSPS for Young Scientists (B), 23710212, and for Specially Promoted Research, 26000002. We thank Midori Hasegawa for the final proofreading.

\section{Author details}

${ }^{1}$ Research and Development Center for Earthquake and Tsunami, Japan Agency for Marine-Earth Science and Technology, Yokohama 236-0001, Japan. ${ }^{2}$ Research Center for Prediction of Earthquakes and Volcanic Eruptions, Graduate School of Science, Tohoku University, Sendai 980-8578, Japan. ${ }^{3}$ International Research Institute of Disaster Sciences, Tohoku 
University, Sendai 980-8579, Japan. ${ }^{4}$ Disaster Mitigation Research Center, Nagoya University, Nagoya 464-8601, Japan.

\section{Received: 16 January 2014 Accepted: 28 May 2014} Published: 16 June 2014

\section{References}

Ampuero JP, Rubin AM (2008) Earthquake nucleation on rate state faults - aging and slip laws. J Geophys Res 113, B01302, doi:10.1029/2007JB005082

Ariyoshi K, Matsuzawa T, Hasegawa A (2007) The key frictional parameters controlling spatial variations in the speed of postseismic-slip propagation on a subduction plate boundary. Earth Planet Sci Lett 256:136-146, doi:10.1016/j. epsl.2007.01.019

Ariyoshi K, Hori T, Ampuero JP, Kaneda Y, Matsuzawa T, Hino R, Hasegawa A (2009) Influence of interaction between small asperities on various types of slow earthquakes in a 3-D simulation for a subduction plate boundary. Gondwana Res 16(3-4):534-544, doi:10.1016/j.gr.2009.03.006

Ariyoshi K, Matsuzawa T, Ampuero JP, Nakata R, Hori T, Kaneda Y, Hasegawa A (2012) Migration process of very low-frequency events based on a chain-reaction model and its application to the detection of preseismic slip for megathrust earthquakes. Earth Planets Space 64(8):693-702, doi:10.5047/ eps.2010.09.003

Ariyoshi K, Nakata R, Matsuzawa T, Hino R, Hori T, Hasegawa A, Kaneda Y (2013) The detectability of shallow slow earthquakes by the Dense Oceanfloor Network system for Earthquakes and Tsunamis (DONET) in Tonankai district. Japan Mar Geophys Res, doi:10.1007/s11001-013-9192-6

Blanpied ML, Marone CJ, Lockner DA, Byerlee JD, King DP (1998) Quantitative measure of the variation in fault rheology due to fluid-rock interactions. J Geophys Res 103:9691-9712

Dieterich JH (1979) Modeling of rock friction: 1. Experimental results and constitutive equations. J Geophys Res 84:2161-2168

Evans EL, Meade BJ (2012) Geodetic imaging of coseismic slip and postseismic afterslip: sparsity promoting methods applied to the great Tohoku earthquake. Geophys Res Lett 39, L11314, doi:10.1029/2012GL051990

Furumura T, Imai K, Maeda T (2011) A revised tsunami source model for the 1707 Hoei earthquake and simulation of tsunami inundation of Ryujin Lake, Kyushu, Japan. J Geophys Res 116, B02308, doi:10.1029/2010JB007918

Hasegawa A, Yoshida K, Okada T (2011) Nearly complete stress drop in the 2011 Mw9.0 off the Pacific coast of Tohoku earthquake. Earth Planets Space 63 (7):703-707, doi:10.5047/eps.2011.06.007, 2011

Hayes GP, Bergman E, Kendra LJ, Benz HM, Brwon L, Meltzer AS (2013) Seismotectonic framework of the 2010 February 27 Mw 8.8 Maule, Chile earthquake sequence. Geophys J Int 195(2):1034-1051, doi:10.1093/gji/ ggt238

Hyndman RD, Yamano M, Oleskevich DA (1997) The seismogenic zone of subduction thrust faults. Isl Arc 6(3):244-260

Ide S, Beroza GC, Shelly DR, Uchide T (2007) A new scaling law for slow earthquakes. Nature 447:76-79, doi:10.1038/nature05780

Igarashi T, Matsuzawa T, Umino N, Hasegawa A (2001) Spatial distribution of focal mechanisms for interplate and intraplate earthquake associated with the subducting Pacific plate beneath the northeastern Japan arc: a triple-planed deep seismic zone. J Geophys Res 106(B2):2177-2191, doi:10.1029/ 2000JB900386

Ito Y, Obara K, Shiomi K, Sekinie S, Hirose H (2007) Slow earthquakes coincident with episodic tremors and slow slip events. Science 315:503-506, doi:10.1126/science.1134454

Iwamori H, Nakakuki T (2013) Fluid processes in subduction zones and water transport to the deep mantle. In: Karato S (ed) Physics and chemistry of the deep Earth, chap 13. Wiley, Chichester, doi:10.1002/9781118529492.ch13

Katayama I, Terada T, Okazaki K, Tanikawa W (2012) Episodic tremor and slow slip potentially linked to permeability contrast at the Moho. Nat Geosci 5:731-734, doi:10.1038/NGEO1559

Kato N, Hirasawa T (1997) A numerical study on seismic coupling along subduction zones using a laboratory-derived friction law. Phys Earth Planet Int 102:51-68

Kato A, lidaka T, Ikuta R, Yoshida Y, Katsumata K, Iwasaki T, Sakai S, Thurber C, Tsumura N, Yamaoka K, Watanabe T, Kunitomo T, Yamazaki F, Okubo M, Suzuki S, Hirata N (2010) Variations of fluid pressure within the subducting oceanic crust and slow earthquakes. Geophys Res Lett 37, L14310, doi:10.1029/2010GL043723
Kido M, Osada Y, Fujimoto H, Hino R, Ito Y (2011) Trench-normal variation in observed seafloor displacements associated with the 2011 Tohoku-Oki earthquake. Geophys Res Lett 38, L24303, doi:10.1029/2011GL050057

Kikuchi M, Nakamura M, Yoshikawa K (2003) Source rupture processes of the 1944 Tonankai earthquake and the 1945 Mikawa earthquake derived from low-gain seismograms. Earth Planets Space 55:159-172

Kohlstedt DL, Evans B, Mackwell SJ (1995) Strength of the lithosphere: constraints imposed by laboratory experiments. J Geophys Res 100(B9):17587-17602

Lay T, Kanamori H, Ruff $L$ (1982) The asperity model and the nature of large subduction zone earthquakes. Earthq Pred Res 1:3-71

Maccaferri F, Rivalta E, Passarelli L, Jonsson S (2013) The stress shadow induced by the 1975-1984 Krafla rifting episode. J Geophys Res 118:1109-1121, doi:10.1002/jgrb.50134

Matsuzawa T, Hirose H, Shibazaki B, Obara K (2010) Modeling short- and long-term slow slip events in the seismic cycles of large subduction earthquakes. J Geophys Res 115(B12), B12301, doi:10.1029/2010JB007566

Matsuzawa T, Asano Y, Obara K (2012) Shallow very low frequency earthquakes off the Pacific coast of Tohoku, Japan., Abstract of 2012 Fall Meeting AGU, S41D-07

Murotani S (2003) Rupture processes of large Fukushima-Oki earthquakes in 1938. University of Tokyo, MSc thesis

Nakanishi A, Kodaira S, Miura S, Ito A, Sato T, Park JO, Kido Y, Kaneda Y (2008) Detailed structural image around splay-fault branching in the Nankai subduction seismogenic zone: results from a high-density ocean bottom seismic survey. I Geophys Res 113, B03105

NIED (National Research Institute for Earth Science and Disaster Prevention) (2012) Activity of shallow very-low-frequency earthquakes in and around Japan (June-October, 2011). Report of The Coordinating Committee for Earthquake Prediction (CCEP) 87:5-7, written in Japanese with captions in English

NIED (National Research Institute for Earth Science and Disaster Prevention) (2014) Activity of shallow very-low-frequency earthquakes in and around Japan (May-October, 2013). Report of The Coordinating Committee for Earthquake Prediction (CCEP) 89:5-7, written in Japanese with captions in English

Obara K, Sekine S (2009) Characteristic activity and migration of episodic tremor and slow-slip events in central Japan. Earth Planets Space 61:853-862

Okada Y (1992) Internal deformation due to shear and tensile faults in a halfspace. Bull Seism Soc Am 82:1018-1040

Ozawa S, Nishimura T, Suito H, Kobayashi T, Tobita M, Imakiire T (2011) Coseismic and postseismic slip of the 2011 magnitude-9 Tohoku-Oki earthquake. Nature 475:373-376, doi:10.1038/nature10227

Rice JR (1993) Spatio-temporal complexity of slip on a fault. J Geophys Res 98:9885-9907

Rubin AM, Ampuero JP (2005) Earthquake nucleation on (aging) rate and state faults. J Geophys Res 110, B11312, doi:10.1029/2005JB003686

Ruina A (1983) Slip instability and state variable friction laws. J Geophys Res 88:10359-10370

Sato M, Ishikawa T, Ujihara N, Yoshida S, Fujita M, Mochizuki M, Asada A (2011) Displacement above the hypocenter of the 2011 Tohoku-Oki Earthquake. Science 332(6036):1395, doi:10.1126/science.1207401

Savage JC (1983) A dislocation model of strain accumulation and release at a subduction zone. J Geophys Res 88:4984-4996

Scholz CH (1990) The mechanics of earthquakes and faulting. Cambridge University Press, Cambridge, p 439

Schwartz SY, Rokosky JM (2007) Slow slip events and seismic tremor at circumPacific subduction zones. Rev Geophys 45, RC3004, doi:10.1029/ 2006RG000208

Shibazaki B, Shimamoto T (2007) Modeling of short-interval silent slip events in deep subduction interfaces considering the frictional properties at the unstable-stable transition regime. Geophys J Int 171:191-205

Shibazaki B, Matsuzawa T, Tsusumi A, Ujiie K, Hasegawa A, Ito Y (2011) 3D modeling of the cycle of a great Tohoku-oki earthquake, considering frictional behavior at low to high slip velocities. Geophys Res Lett 38, L21305, doi:10.1029/2011GL049308

Sugioka H, Okamoto T, Nakamura T, Ishihara Y, Ito A, Obana K, Kinoshita M, Nakahigashi K, Shinohara M, Fukao Y (2012) Tsunamigenic potential of the shallow subduction plate boundary inferred from slow seismic slip. Nat Geosci 5:414-418, doi:10.1038/NGEO1466

Uchida N, Nakajima J, Hasegawa A, Matsuzawa T (2009) What controls interplate coupling?: evidence for abrupt change in coupling across a border between 
two overlying plates in the N. E. Japan subduction zone. Earth Planet Sci Lett 283:111-121, doi:10.1016/j.epsl.2009.04.003

Wessel P, Smith WHF (1998) New, improved version of the Generic Mapping Tools released. Eos Trans AGU 79:579

Wiseman K, Bürgmann R (2011) Stress and seismicity changes on the Sunda megathrust preceding the $2007 \mathrm{Mw} 8.4$ earthquake. Bull Seism Soc Am 101(1):313-326

Yagi Y, Fukahata Y (2011) Rupture process of the 2011 Tohoku-oki earthquake and absolute elastic strain release. Geophys Res Lett 38, L19307, doi:10.1029/ 2011GL048701

Yamanaka Y, Kikuchi M (2003) Source process of the recurrent Tokachi-oki earthquake on September 26, 2003, inferred from teleseismic body waves. Earth Planet Space 55:e21-e24

Yamanaka Y, Kikuchi M (2004) Asperity map along the subduction zone in northeastern Japan inferred from regional seismic data. J Geophys Res 109, B07307, doi:10.1029/2003JB002683

doi:10.1186/1880-5981-66-55

Cite this article as: Ariyoshi et al: A trial derivation of seismic plate coupling by focusing on the activity of shallow slow earthquakes. Earth, Planets and Space 2014 66:55.

\section{Submit your manuscript to a SpringerOpen ${ }^{\circ}$ journal and benefit from:}

- Convenient online submission

- Rigorous peer review

- Immediate publication on acceptance

- Open access: articles freely available online

- High visibility within the field

- Retaining the copyright to your article

Submit your next manuscript at $\gg$ springeropen.com 